\title{
A Queiloscopia como técnica de identificação humana: Uma revisão sistemática da
}

\author{
literatura \\ Queiloscopy as a human identification technique: A systematic literature review \\ Queiloscopia como técnica de identificación humana: Una revisión sistemática de la literatura
}

Recebido: 21/06/2021 | Revisado: 30/06/2021 | Aceito: 06/07/2021 | Publicado: 17/07/2021

Anderson Nobrega dos Santos

ORCID: https://orcid.org/0000-0001-6454-3846 Universidade Federal da Paraíba, Brasil

E-mail: andersonnobrega1997@hotmail.com

Tainá Nascimento Falcão

ORCID: https://orcid.org/0000-0002-3326-063X Universidade Federal da Paraíba, Brasil

E-mail: taina.falcao@hotmail.com

Laíse Nascimento Correia Lima

ORCID: https://orcid.org/0000-0002-1773-847X Universidade Federal da Paraíba, Brasil E-mail: laise.lima@academico.ufpb.com

Thiago Isidro Vieira

ORCID: https://orcid.org/0000-0003-4824-9131 Universidade Federal da Paraíba, Brasil E-mail: thiago_isidro@yahoo.com.br

Bianca Marques Santiago

ORCID: https://orcid.org/0000-0001-9559-913X Universidade Federal da Paraíba, Brasil E-mail: bianca.santiago@yahoo.com.br

\begin{abstract}
Resumo
A identificação humana, uma das áreas mais investigadas no campo forense, se baseia na aplicação de técnicas e métodos para individualizar sujeitos. A queiloscopia é um método de identificação humana baseada no estudo das características morfológicas dos sulcos labiais, considerados padrões únicos assim como a impressão digital. Avaliouse as evidências científicas existentes acerca da queiloscopia como método de identificação humana por meio de uma revisão sistemática, baseada no protocolo do Preferred Report of Systematic Reviews and Meta-Analysis (PRISMA), sendo as buscas realizadas nas bases: Web of Science, Pubmed, Scopus, Cochrane, Lilacs e Sigle, seguindo a estratégia do acrônimo PICO/PECO. Foram recuperados 10.715 registros e, após a remoção das duplicatas e da triagem inicial, 26 artigos seguiram para leitura na íntegra. Ao final, permaneceram 22 artigos, dos quais 21 tiveram delineamento transversal e 1 longitudinal. A avaliação da qualidade metodológica, realizada por meio do QUADAS-2, indicou que todos os estudos atenderam a mais de $80 \%$ dos requisitos de qualidade. Os sistemas de classificação utilizados para análise variaram entre os estudos, sendo o de Suzuki e Tsuchihashi o mais utilizado (82\%). Para buscar os padrões de impressão labial e a sua unicidade, os estudos utilizaram análises estatísticas que envolveram 7 tipos de testes e em 5 estudos foi utilizado estatística descritiva. Conclui-se que a queiloscopia é um método eficaz para a identificação humana de baixo custo e maior rapidez. Entretanto, não é eficaz para estimar o sexo e ainda são necessárias evidências para confirmar sua aplicabilidade na análise da relação parental.
\end{abstract}

Palavras-chave: Queiloscopia; Identificação humana; Odontologia forense; Revisão sistemática.

\begin{abstract}
The human identification, one of the most searched areas on the forensic field, is based on the application of methods and techniques to individualize people. The cheiloscopy is a method of human identification based in the study of morphological characteristics of labial grooves, considered unique patterns for every person, same as finger prints. We evaluated the existing scientific evidence about cheiloscopy as a method of human identification through a systematic review, based on the Preferred Report of Systematic Reviews and Meta-Analysis (PRISMA) protocol. The searches were performed in the databases: Web of Science, Pubmed, Scopus, Cochrane, Lilacs and Sigle following the strategy of the acronym PICO/PECO. 10,715 records were recovered and, after removing duplicates and initial screening, 26 articles were read in full. Ultimately, 22 articles remained, of which 21 had a cross-sectional and 1 longitudinal design. The assessment of methodological quality, performed by the QUADAS-2, indicated that all studies met more than $80 \%$ of the quality requirements. The classification systems used for analysis varied between the studies, with Suzuki and Tsuchihashi being the most used (82\%). To search the more common standards of labial grooves and their unicity, the studies used statistical analysis that involved 7 types of tests and in 5 studies were used descriptive statistics. We
\end{abstract}


concluded that cheiloscopy is an effective method for human identification, being faster and low budget. However, the method is not effective to estimate the sex and evidences are still needed to confirm it's applicability on the analysis of the parental relation.

Keywords: Cheiloscopy; Human identification; Forensic dentistry; Systematic review.

\section{Resumen}

La identificación humana, una de las más importantes labores en el campo forense, se basa en la aplicación de técnicas y métodos para individualizar un sujeto. Una de ellas, la queiloscopía, estudia los patrones morfológicos característicos de los surcos labiales, únicos, como las huellas dactilares. Se evaluaron las evidencias científicas sobre la queiloscopía, mediante una revisión sistemática, según el protocolo Preferred Report of Systematic Reviews and Meta-Analysis (PRISMA), con búsquedas realizadas en las bases de datos Web of Science, Pubmed, Scopus, Cochrane, Lilacs y Sigle, siguiendo la estrategia PICO/PECO. Fueron localizados 10.715 registros y, después de la primera clasificación y eliminación de los duplicados, se leyeron 26 artículos en su totalidad. Finalmente, quedaron 22 artículos, de los cuales 21 tenían un diseño transversal y 1, longitudinal. La evaluación de la calidad metodológica, valiéndose del QUADAS2, indicó que todos los estudios cumplían con más del $80 \%$ de los requisitos de calidad. Los sistemas de clasificación utilizados para el análisis variaron, siendo Suzuki y Tsuchihashi, los más frecuentes (82\%). Para investigar patrones de huellas labiales y su unicidad, se utilizaron 7 tipos de análisis estadísticos, y en 5 estudios, sólo se empleó estadística descriptiva. Se concluyó que la queiloscopía es un método rápido, eficaz y de bajo costo para la identificación humana. Sin embargo, no resulta de utilidad para estimar el sexo, siendo necesarias más investigaciones, para confirmar su aplicabilidad en el análisis del parentesco.

Palabras clave: Queiloscopia; Identificación humana; Odontología forense; Revisión sistemática.

\section{Introdução}

A identificação humana é uma das áreas mais investigadas e debatidas dentro do campo forense. Nela, se procura técnicas e métodos para individualizar o sujeito frente a seus restos, em casos de acidentes, violência sexual e/ou infantil, suspeitas de atos criminosos, entre outros (Singh, Gupta, Sardana, Balappanavar \& Malhotra, 2012; Privadharshini, Ambika, Sekar, Mohanbabu, Sabarinath \& Pavithra, 2018). Os odontolegistas utilizam métodos de identificação baseados em comparações científicas e consideradas verdadeiras, utilizando informações anteriormente conhecidas (Priyadharshini et al., 2018).

Para que um método de identificação seja considerado aplicável, este deve atender a requisitos biológicos e técnicos que o classificarão como confiável ou não para uso no meio forense, são eles: os requisitos da unicidade (apenas um único indivíduo possui determinada característica), imutabilidade (a característica não deve se alterar como passar do tempo), perenidade (deve persistir à ação do tempo), praticabilidade (a forma de obter o registro de uma característica deve ser de fácil aplicação e baixo custo), e a classificabilidade (arquivamento dos registros obtidos para posterior análise) (Tornavoi \& da Silva, 2010; Gioster-Ramos, Silva, Nascimento \& da Silva Fernandes, 2021).

Nem sempre é possível obter as impressões digitais de um indivíduo, principalmente em casos em que há corpos carbonizados ou ossadas. Assim como não seja possível a análise de DNA, seja por demandar tempo ou por seu alto custo, sendo necessárias outras alternativas (Gioster-Ramos et al. 2021). Existem diversos métodos e técnicas de identificação humana que são empregados no campo da odontologia legal e que respondem aos pré-requisitos necessários, como a identificação através da documentação odontológica do indivíduo, as marcas de mordida, a análise da saliva, análise das rugas palatinas, análise dos seios da face e a estimativa de idade através dos estágios de mineralização dental (Tornavoi \& da Silva, 2010; Bangi, Ginjupally, Nadendla \& Vadla, 2017; Page, Lain, Kemp \& Taylor, 2018).

A queiloscopia é considerada um método de identificação humana que foi descrita pela primeira vez em 1902 por R. Fisher, sendo definida como o estudo das características morfológicas dos sulcos ou ranhuras labiais, considerados padrões únicos para cada pessoa assim como a sua impressão digital (Verghese, Somasekar, \& Umesh Babu, 2010; Reddy, 2011; Singh et al, 2012). Um forte exemplo de sua utilização ocorreu na década de 1950, quando Le Moya Snydes, especialista forense da Califórnia, associou os sulcos labiais à identificação humana ao investigar, em um caso de acidente aéreo, a impressão labial 
encontrada no para brisas do avião e compará-la com a da vítima, comprovando que as características formadas pelos sulcos labiais podem ser individuais (Barros, 2006; Caldas, Magalhães \& Afonso, 2007; Reddy, 2011; Singh et al., 2012).

Os autores Yasuo Tsuchihasi e Kazuo Suzuki em seus estudos na Tokio University (1968-1971) também confirmaram, por meio do exame labial de 1364 indivíduos com idades entre 3 e 60 anos, que as impressões labiais são únicas e imutáveis para cada indivíduo. Estas características (unicidade e imutabilidade) são necessárias no que tange à identificação humana e eliminatórias quando, em perícias criminais com mais de um suspeito, excluem àqueles onde não há correspondência de suas características na análise.

O objetivo desta revisão sistemática é avaliar as evidências científicas existentes acerca da queiloscopia como método de identificação humana a fim subsidiar sua implementação, ou não, na rotina da investigação forense. Neste contexto, a pergunta norteadora dessa revisão sistemática foi: “A queiloscopia é um método eficaz para a identificação humana?”

\section{Metodologia}

Esta revisão foi registrada no banco de dados Open Science Framework (DOI 10.17605/OSF.IO/U3W7A). A metodologia foi desenvolvida de acordo com o Manual da Cochrane para Revisões Sistemáticas de Estudos de Acurácia de Testes Diagnósticos (https://training.cochrane.org/resource/cochrane-handbook-systematic-reviews-diagnostic-test-accuracy) e redigida seguindo o protocolo do Preferred Report of Systematic Reviews and Meta-Analysis (PRISMA) (Moher, Liberati, Tetzlaff, Altman \& Prisma Group, 2009), que preconiza os seguintes itens: estratégia de busca, triagem de estudos com base em critérios de inclusão e exclusão, seleção de artigos, avaliação metodológica da qualidade e avaliação de risco de viés de artigos selecionados, extração de dados e tabulação, além da síntese quantitativa (metanálise) e avaliação do grau de certeza da evidência, quando possíveis.

\subsection{Estratégia de busca}

Os artigos publicados até dezembro de 2019, sem restrição relacionada à data ou idioma da publicação, foram selecionados com base na estratégia PICO / PECO, em que P refere-se ao problema ou população, I ou E à intervenção ou exposição, $\mathrm{C}$ ao controle e $\mathrm{O}$ ao (s) resultado (s). As pesquisas bibliográficas foram realizadas por dois revisores nas seguintes bases de dados: Pubmed, Scopus, Cochrane Library, Web of Science, LILACS e System for Information on Grey Literature (SIGLE). Os tópicos foram combinados entre si pelo operador booleano "AND" e cada tópico, correspondente a um dos componentes do acrônimo PICO/PECO, foi criado usando o operador "OR" para combinar os termos utilizados no banco de dados de indexação (termos MeSH). O primeiro tópico refere-se às diferentes maneiras de mencionar o interesse da população na questão central desta revisão sistemática e incluiu a seguinte palavra-chave: "humans". O segundo tópico (I / E), ou seja, o método utilizado foi a queiloscopia, no qual foram incluídas as seguintes palavras-chave: "forensic sciences", "forensic dentistry", "forensic odontology", "lip prints", "traces" e "cheiloscopy". O terceiro tópico consistiu em O, o desfecho, que foi a identificação humana com as seguintes palavras-chave: "forensic anthropology", "determination" e "human identification". Também se procedeu a busca manual da lista de referências dos artigos selecionados para identificar estudos que não foram recuperados na pesquisa inicial. Como cada base de dados apresenta particularidades para execução da busca, a Tabela 1 ilustra a estratégia de busca específica adotada em cada uma das bases. 
Tabela 1. Estratégia de busca utilizada em cada uma das bases eletrônicas para realização das pesquisas por artigos.

\begin{tabular}{|c|c|}
\hline BASE DE DADOS & PALAVRA-PASSE \\
\hline MEDLINE-PUBMED & 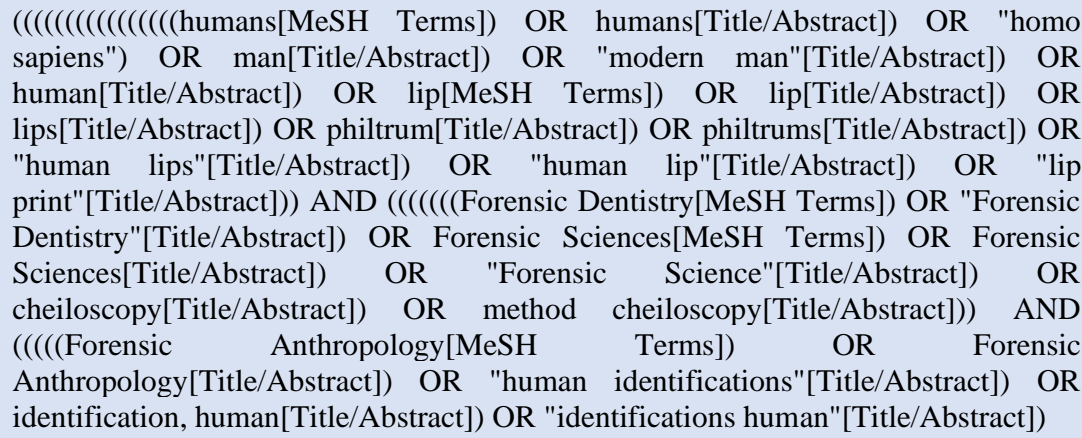 \\
\hline SCOPUS & $\begin{array}{l}\text { ( humans OR "homo sapiens" OR man OR "modern man" OR human OR lip } \\
\text { OR lips OR philtrum OR philtrums OR "human lips" OR "human lip" OR "lip } \\
\text { print" ) AND TITLE-ABS-KEY ( "Forensic Dentistry" OR "Forensic Sciences" OR } \\
\text { "Forensic Sciences" OR "Forensic Science" OR "cheiloscopy" OR "method } \\
\text { cheiloscopy" ) AND TITLE-ABS-KEY ( "Forensic Anthropology" OR "human } \\
\text { identifications" OR "identification, human" OR "identifications human" ) }\end{array}$ \\
\hline
\end{tabular}

\begin{tabular}{|c|c|}
\hline \multirow{14}{*}{ COCHRANE LIBRARY } & MeSH descriptor: [Humans] explode all trees \\
\hline & humans OR "homo sapiens" OR man OR "modern man" OR human \\
\hline & MeSH descriptor: [Lip] explode all trees \\
\hline & $\begin{array}{l}\text { \#4 lip OR lips OR philtrum OR philtrums OR "human lips" OR "human lip" } \\
\text { OR "lip prints" }\end{array}$ \\
\hline & \#1 OR \#2 OR \#3 OR \#4 \\
\hline & MeSH descriptor: [Forensic Dentistry] explode all trees \\
\hline & Forensic Dentistry \\
\hline & MeSH descriptor: [Forensic Sciences] explode all trees \\
\hline & $\begin{array}{l}\text { \#9 "Forensic Sciences" OR "Forensic Science" OR "Cheiloscopy" OR "Method } \\
\text { cheiloscopy" }\end{array}$ \\
\hline & \#6 OR \#7 OR \#8 OR \#9 346 \\
\hline & MeSH descriptor: [Forensic Anthropology] explode all trees \\
\hline & $\begin{array}{l}\# 12 \quad \text { "Forensic Anthropology" OR "human identifications" OR "identification, } \\
\text { human" OR "identifications human" } 50\end{array}$ \\
\hline & \#11 OR \#12 \\
\hline & \#14 \#5 AND \#10 AND \#13 8 \\
\hline WEB OF SCIENCE & $\begin{array}{l}\text { TS=(humans OR "homo sapiens" OR man OR "modern man" OR human OR } \\
\text { lip OR lips OR philtrum OR philtrums OR "human lips" OR "human lip" OR } \\
\text { "lip print") AND TS=( "Forensic Dentistry" OR "Forensic Sciences" OR "Forensic } \\
\text { Sciences" OR "Forensic Science" OR "cheiloscopy" OR "method cheiloscopy" ) } \\
\text { AND TS=( "Forensic Anthropology" OR "human identifications" OR } \\
\text { "identification, human" OR "identifications human" ) }\end{array}$ \\
\hline LILACS & $\begin{array}{l}\text { (tw:((tw:(humanos)) OR (tw:(humans)) OR (tw:(homo sapiens)) OR (tw:(man)) OR } \\
\text { (tw:(modern man)) OR (tw:(human)) OR (tw:(labios)) OR (tw:(lip)) OR (tw:(lips)) } \\
\text { OR (tw:(philtrum)) OR (tw:(philtrums)) OR (tw:(human lip)) OR (tw:(human lips)) } \\
\text { OR (tw:(lip print)))) AND (tw:((tw:(Odontología Forense)) OR (tw:(Ciencias } \\
\text { Forenses)) OR (tw:(Forensic dentistry)) OR (tw:(Forensic sciences)) OR } \\
\text { (tw:(Forensic science)) OR (tw:(Cheiloscopy)) OR (tw:(Method Cheiloscopy)))) } \\
\text { AND (tw:((tw:(Antropología Forense)) OR (tw:(Forensic Antropology)) OR } \\
\text { (tw:(Human Identifications)) OR (tw:(identification, human)) OR (tw:(identifications } \\
\text { humas)))) }\end{array}$ \\
\hline SIGLE & $\begin{array}{l}\text { (lip OR "human lips" OR "human lip" OR "lip print") AND ( "Forensic Dentistry" } \\
\text { OR "Forensic Sciences" OR "cheiloscopy" OR "method cheiloscopy" ) AND } \\
\text { ( "Forensic Anthropology" OR "human identifications" OR "identifications human") }\end{array}$ \\
\hline
\end{tabular}

Fonte: Autores. 


\subsection{Critérios de elegibilidade}

Foram incluídos estudos que tivessem analisados os lábios dos indivíduos, independentemente de sua idade, para fins de identificação humana. Os critérios de exclusão foram: editoriais, revisões da literatura, relatos de caso, série de casos e estudos analíticos que não apresentavam resultados quanto a aplicabilidade do método da queiloscopia para fins forenses. Adicionalmente, estudos demonstrando resultados repetidos de um mesmo estudo original foram excluídos.

Dois examinadores, responsáveis pela pesquisa nas bases, realizaram, independentemente, a seleção inicial dos artigos a partir da análise de títulos e resumos. Posteriormente, os artigos pré-selecionados foram lidos na íntegra para verificar sua elegibilidade. Em casos de discordância, obteve-se consenso na discussão com um terceiro examinador.

\subsection{Extração de dados}

Utilizou-se um formulário padronizado para extração dos dados, que incluiu, entre outras informações: nome do autor do estudo, tamanho da amostra, objetivos, método de coleta das impressões labiais, classificação utilizada, a finalidade forense e a conclusão. Todas as etapas desta revisão sistemática foram realizadas de forma independente por dois examinadores e todas as possíveis divergências foram resolvidas com a avaliação, discussão e consenso de um terceiro examinador.

\subsection{Avaliação da qualidade metodológica e do risco de vieses dos estudos}

A avaliação da qualidade metodológica e do risco de vieses dos estudos selecionados foi realizada de forma independente pelos mesmos dois examinadores, a partir da utilização do instrumento QUADAS 2 (https://www.nice.org.uk/article/pmg6b/chapter/Appendix-F-Methodologychecklist-the-QUADAS2-tool-for-studies-ofdiagnostic-test-accuracy), o qual é recomendado para estudos de acuraria de testes diagnósticos.

\section{Resultados}

Um total de 10.715 registros foi recuperado das bases de dados, dos quais 7.675 foram submetidos a triagem inicial após exclusão de registros duplicados. Após a triagem inicial por títulos e resumos, restaram 26 artigos que foram selecionados para análise em texto completo e verificação quanto aos critérios de elegibilidade. Destes, 4 artigos foram excluídos pelos seguintes motivos: um deles correspondia a uma calibração entre examinadores para análise de impressões; em outro a estimativa do sexo era o foco principal do estudo; o terceiro compreendia uma análise da prevalência e correlação das impressões labiais, digitais e grupos sanguíneos ABO; e o último tratava-se da criação de banco de dados com impressões labiais, palatais e digitais. Dos 22 artigos selecionados para a síntese qualitativa, todos possuíam como finalidade forense principal a identificação humana, destes 15 também estudaram, adicionalmente, a estimativa do sexo, conforme apontado na Figura 1. 
Figura 1. Diagrama de fluxo PRISMA dos resultados da pesquisa nos bancos de dados.

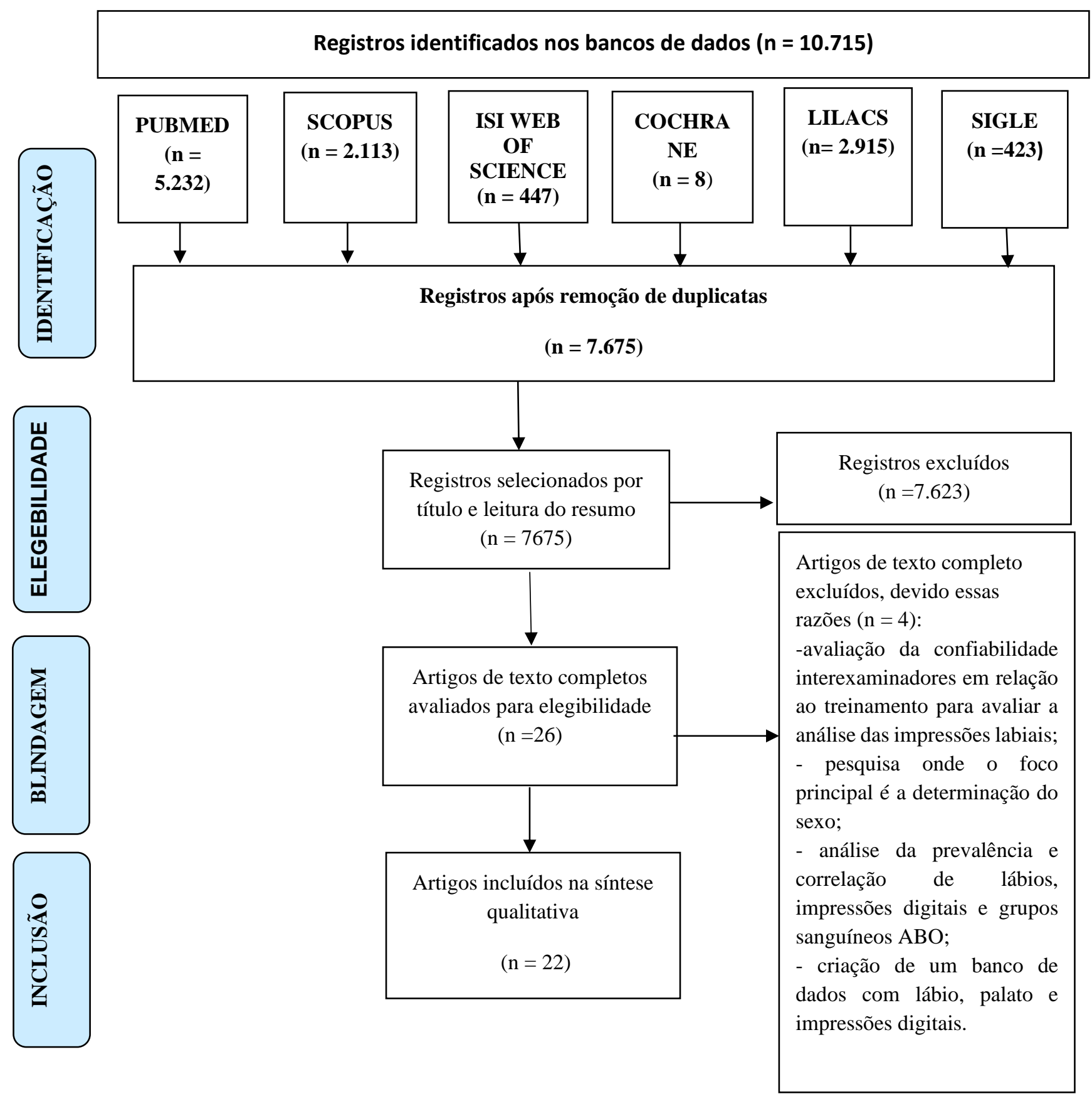

Fonte: Autores.

As características dos estudos selecionados estão descritas na Tabela 1, como o nome do(s) autor(es) e o ano da sua publicação, o tipo de estudo, o número da população amostral, o objetivo, a sua finalidade forense, a forma como ocorreu a coleta da impressão, considerações importantes elencadas pelos revisores desta revisão após a leitura na íntegra dos artigos e sua conclusão.

Quanto ao delineamento do estudo, 21 foram estudos transversais e apenas um foi longitudinal. O tamanho da amostra variou de 30 à 966 indivíduos, assim como o ano de publicação variou de 2006 à 2019. 
Tabela 1. Extração dos dados dos estudos incluídos na fase de avaliação qualitativa.

\begin{tabular}{|c|c|c|c|c|c|c|c|c|}
\hline Autor/Ano & Tipo de Estudo & Amostra & Objetivo & Fim Forense & $\begin{array}{c}\text { Coleta da impressão } \\
\text { labial }\end{array}$ & $\begin{array}{l}\text { Análise e comparação } \\
\text { da impressão }\end{array}$ & $\begin{array}{l}\text { Outras considerações } \\
\text { importantes }\end{array}$ & Conclusão \\
\hline $\begin{array}{c}\text { Jain, S. et al./ } \\
2018\end{array}$ & Transversal & $\mathrm{N}=80$ & $\begin{array}{l}\text { Novo método p/ } \\
\text { mostrar a unicidade } \\
\text { das impressões } \\
\text { labiais e os padrões } \\
\text { predominantes em } \\
\text { indivíduo de } \\
\text { diferentes estados da } \\
\text { Índia. }\end{array}$ & $\begin{array}{l}\text { Identificação } \\
\text { Humana }\end{array}$ & $\begin{array}{l}\text { Cada indivíduo } \\
\text { aplicou batom e a } \\
\text { impressão labial foi } \\
\text { coletada } \\
\text { pressionando os } \\
\text { lábios em papel e } \\
\text { fotografada. }\end{array}$ & $\begin{array}{l}\text { Cada img foi tratada e } \\
\text { convertida em escala de } \\
\text { cinza, valores num. } \\
\text { foram atribuídos a partir } \\
\text { dos pixels e obteve-se a } \\
\text { média desses valores } \\
\text { para cada indivíduo. }\end{array}$ & $\begin{array}{l}\text { A média obtida foi } \\
\text { única para cada } \\
\text { indivíduo, mas } \\
\text { padrões semelhantes } \\
\text { foram observados } \\
\text { entre os indivíduos do } \\
\text { mesmo estado. }\end{array}$ & $\begin{array}{l}\text { Cada impressão } \\
\text { labial é única e difere } \\
\text { significativamente de } \\
\text { região para região na } \\
\text { Índia. }\end{array}$ \\
\hline $\begin{array}{c}\text { Chaudhari, } \\
\text { S.H. et al./ } \\
2017\end{array}$ & Transversal & $\mathrm{N}=150$ & 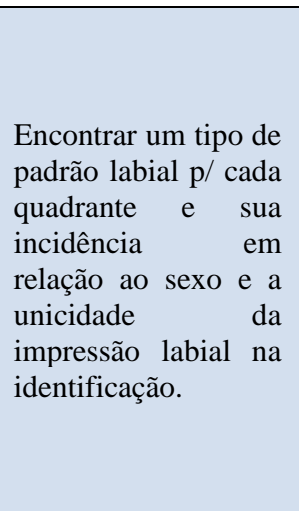 & $\begin{array}{l}\text { Identificação } \\
\text { Humana/ } \\
\text { Determ. de } \\
\text { sexo }\end{array}$ & $\begin{array}{l}\text { Cada indivíduo } \\
\text { aplicou batom e a } \\
\text { impressão labial foi } \\
\text { coletada } \\
\text { pressionando } \\
\text { lábios em papel. A } \\
\text { impressão } \\
\text { dividida em } \\
\text { quadrantes. }\end{array}$ & $\begin{array}{l}\text { O padrão labial foi } \\
\text { analisado segundo a } \\
\text { classificação de Suzuki } \\
\text { e Tsuchihashi e a } \\
\text { estimativa de sexo } \\
\text { segundo Vahanwala et } \\
\text { al. }\end{array}$ & $\begin{array}{l}\text { O padrão de impressão } \\
\text { labial mais comum foi } \\
\text { tipo I, seguido do tipo } \\
\text { II, tipo I ', tipo III e tipo } \\
\text { IV em ambos os sexos } \\
\text { e era comum em vários } \\
\text { compartimentos. }\end{array}$ & $\begin{array}{l}\text { 1. Nenhum indivíduo } \\
\text { teve o mesmo tipo de } \\
\text { impressão em todos } \\
\text { os } \\
\text { quadrantes. } \\
2 . \text { Não houve } \\
\text { distribuição por sexo } \\
\text { entre o padrão de } \\
\text { impressão labial. } \\
\text { 3. A impressão labial } \\
\text { é única p/ cada } \\
\text { indivíduo, pois não } \\
\text { há duas ou mais } \\
\text { similares entre si. }\end{array}$ \\
\hline $\begin{array}{c}\text { Kumar, G.S. } \\
\text { et al./2012 }\end{array}$ & Transversal & $\mathrm{N}=60$ & $\begin{array}{l}\text { Determinar } \\
\text { unicidade da } \\
\text { impressão labial e o } \\
\text { padrão predominante } \\
\text { em uma população de } \\
\text { Pondicherry, India. }\end{array}$ & $\begin{array}{l}\text { Identificação } \\
\text { Humana/ } \\
\text { Determ. de } \\
\text { sexo }\end{array}$ & $\begin{array}{l}\text { Cada indivíduo } \\
\text { aplicou batom e a } \\
\text { impressão labial foi } \\
\text { coletada } \\
\text { pressionando os } \\
\text { lábios em papel. }\end{array}$ & $\begin{array}{l}\text { Foi considerada apenas } \\
\text { a região central da } \\
\text { impressão }(\sim 10 \mathrm{~mm}) \text {. O } \\
\text { padrão labial foi } \\
\text { analisado segundo a } \\
\text { classificação } \text { de } \\
\text { Tsuchihashi. Teste } t \text { para } \\
\text { verificar diferença entre } \\
\text { os sexos. }\end{array}$ & & $\begin{array}{l}\text { O padrão de } \\
\text { impressão labial é } \\
\text { diferente entre os } \\
\text { sexos. } \\
\text { A impressão labial é } \\
\text { única e não há duas } \\
\text { ou mais semelhantes } \\
\text { entre si. }\end{array}$ \\
\hline $\begin{array}{c}\text { Ragab, A.R. et } \\
\text { al./2013 }\end{array}$ & Transversal & $\begin{array}{l}N=955 \\
(f=720 ; \\
m=235)\end{array}$ & $\begin{array}{l}\text { Determinar o padrão } \\
\text { da impressão labial e } \\
\text { sua unicidade em } \\
\text { uma população } \\
\text { Egípcia. }\end{array}$ & $\begin{array}{l}\text { Identificação } \\
\text { Humana/ } \\
\text { Determ. de } \\
\text { sexo }\end{array}$ & $\begin{array}{l}\text { Cada indivíduo } \\
\text { aplicou batom e a } \\
\text { impressão labial foi } \\
\text { coletada } \\
\text { pressionando os } \\
\text { lábios em papel e } \\
\text { fotografada. }\end{array}$ & $\begin{array}{l}\text { A análise baseou-se na } \\
\text { classificação de Renaud. } \\
\text { A impressão foi dividida } \\
\text { em } 6 \text { áreas topográficas } \\
\text { e as mais laterais foram } \\
\text { excluídas da análise. } \\
\text { Teste } t \text { para verificar } \\
\text { diferença entre os sexos. }\end{array}$ & $\begin{array}{lr}\text { A análise } & \text { das } \\
\text { impressões } & \text { nas } 26 \\
\text { famílias } & \text { estudadas } \\
\text { mostrou } & \\
\text { vários padrões entre os } \\
\text { participantes. } \\
\text { O exame de } 3 \text { gêmeos } \\
\text { idênticos revelou }\end{array}$ & $\begin{array}{lr}\text { Nenhum } r & \text { dos } \\
\text { indivíduos } & \\
\text { apresentou padrões } \\
\text { absolutamente } \\
\text { idênticos. Não houve } \\
\text { associação entre os } \\
\text { padrões } & \text { de } \\
\text { impressões } & \text { labiais }\end{array}$ \\
\hline
\end{tabular}




\begin{tabular}{|c|c|c|c|c|c|c|c|c|}
\hline & & & & & & & $\begin{array}{l}\text { alguma semelhança } \\
\text { nos tipos de sulcos. } \\
\text { A impressão labial é } \\
\text { considerada única, } \\
\text { mesmo em gêmeos e } \\
\text { parentes. }\end{array}$ & $\begin{array}{l}\text { em relação à idade, } \\
\text { sexo e distribuição } \\
\text { geográfica. }\end{array}$ \\
\hline $\begin{array}{c}\text { Augustine, J. } \\
\text { et al./2008 }\end{array}$ & Transversal & $\mathrm{N}=600$ & $\begin{array}{l}\text { Classificar padrões } \\
\text { labiais e documentar } \\
\text { padrões da } \\
\text { população. Avaliar } \\
\text { diferenças sexo, } \\
\text { faixa etária e } \\
\text { verificar se nas } \\
\text { existe algum padrão } \\
\text { hereditário na } \\
\text { impressões labiais. }\end{array}$ & $\begin{array}{l}\text { Identificação } \\
\text { Humanal } \\
\text { Determ. de } \\
\text { sexo }\end{array}$ & $\begin{array}{l}\text { Cada indivíduo } \\
\text { aplicou batom e a } \\
\text { impressão labial foi } \\
\text { coletada } \\
\text { pressionando os } \\
\text { lábios em papel. }\end{array}$ & $\begin{array}{l}\text { Cada impressão labial } \\
\text { foi digitalizada, } \\
\text { invertida e convertida } \\
\text { em escala de cinza. O } \\
\text { padrão labial foi } \\
\text { analisado segundo a } \\
\text { classificação de Suzuki } \\
\text { e Tsuchihashi. }\end{array}$ & 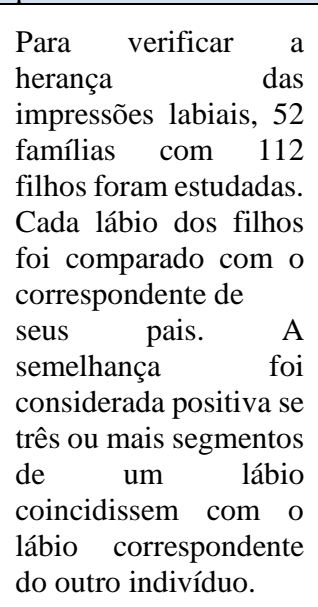 & 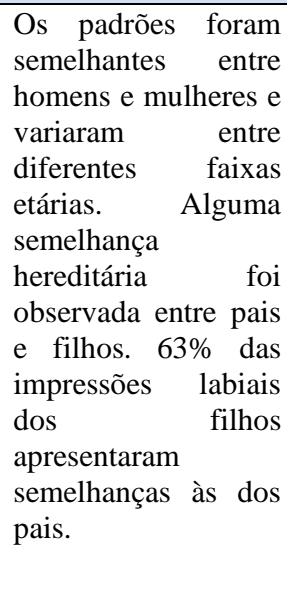 \\
\hline $\begin{array}{l}\text { Nagalaxmi, } V \text {. } \\
\text { et al./2014 }\end{array}$ & Transversal & $N=60$ & $\begin{array}{l}\text { Aplicação da } \\
\text { queiloscopia, } \\
\text { palatoscopia e índice } \\
\text { canino mandibular na } \\
\text { identificação } \\
\text { determinação de } \\
\text { sexo. Também } \\
\text { mostra } \\
\text { variabilidade inter e } \\
\text { intra-observador na } \\
\text { avaliação desses } \\
\text { parâmetros. }\end{array}$ & $\begin{array}{l}\text { Identificação } \\
\text { Humana/ } \\
\text { Determ. de } \\
\text { sexo }\end{array}$ & $\begin{array}{l}\text { Cada indivíduo } \\
\text { aplicou batom e a } \\
\text { impressão labial foi } \\
\text { coletada } \\
\text { pressionando os } \\
\text { lábios em papel. }\end{array}$ & $\begin{array}{l}\text { Cada impressão labial } \\
\text { foi dividida em } 6 \text { áreas. } \\
\text { Os padrões mais } \\
\text { predominantes e } \\
\text { claramente visíveis em } \\
\text { cada zona foram } \\
\text { considerados para } \\
\text { determinação do sexo. A } \\
\text { análise foi feita segundo } \\
\text { a classificação de } \\
\text { Suzuki e Tsuchihashi. }\end{array}$ & $\begin{array}{l}\text { Em } 5 \text { indivíduos foi } \\
\text { observado um padrão } \\
\text { na impressão labial em } \\
\text { três gerações, mas com } \\
\text { distribuição variada, } \\
\text { indicando } \\
\text { singularidade na } \\
\text { mesma família. }\end{array}$ & $\begin{array}{l}\text { Nenhuma impressão } \\
\text { labial mostrou } \\
\text { padrões } \\
\text { distribuição } \\
\text { semelhantes em cada } \\
\text { quadrante. } \\
\text { Observou-se mais de } \\
\text { dois padrões. As } \\
\text { impressões labiais, } \\
\text { os padrões de rugas e } \\
\text { as medidas } \\
\text { odontométricas têm o } \\
\text { potencial na } \\
\text { identificação } \\
\text { humana, onde as } \\
\text { impressões labiais } \\
\text { são mais confiáveis } \\
\text { na determinação de } \\
\text { gênero quando }\end{array}$ \\
\hline
\end{tabular}




\begin{tabular}{|c|c|c|c|c|c|c|c|}
\hline & & & & & & & $\begin{array}{l}\text { comparadas às rugas } \\
\text { palatais e ao índice } \\
\text { do canino. }\end{array}$ \\
\hline $\begin{array}{l}\text { Sharma, P. et } \\
\text { al./2009 }\end{array}$ & Transversal & $\mathrm{N}=100$ & $\begin{array}{l}\text { Verificar o uso de } \\
\text { impressões labiais e } \\
\text { padrão de rugas } \\
\text { palatais } \\
\text { identificação } \\
\text { diferenciação de sexo }\end{array}$ & $\begin{array}{l}\text { Identificação } \\
\text { Humana/ } \\
\text { Determ. de } \\
\text { sexo }\end{array}$ & $\begin{array}{l}\text { Cada indivíduo } \\
\text { aplicou batom e a } \\
\text { impressão labial foi } \\
\text { coletada } \\
\text { pressionando os } \\
\text { lábios em papel }\end{array}$ & $\begin{array}{ll}\text { A análise da impressão } \\
\text { labial baseou-se na } \\
\text { classificação } & \text { de } \\
\text { Tsuchihashi. } & \end{array}$ & 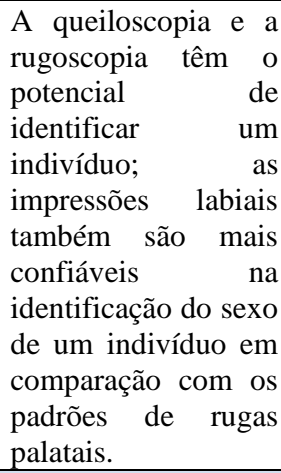 \\
\hline $\begin{array}{c}\text { Oliveira, J.A. } \\
\text { et al./2012 }\end{array}$ & Transversal & $\mathrm{N}=104$ & $\begin{array}{l}\text { Investigar } \\
\text { características as } \\
\text { queiloscópicas de } \\
\text { graduandos da } \\
\text { UFPB, avaliando as } \\
\text { possíveis } \\
\text { divergências entre os } \\
\text { sexos, bem como a } \\
\text { validade do método } \\
\text { na identificação } \\
\text { humana. }\end{array}$ & $\begin{array}{l}\text { Identificação } \\
\text { Humana/ } \\
\text { Determ. de } \\
\text { sexo }\end{array}$ & $\begin{array}{l}\text { Mensuração da } \\
\text { espessura labial com } \\
\text { compasso de ponta } \\
\text { seca. A classificação } \\
\text { das comissuras foi } \\
\text { feita por meio de } \\
\text { fotografias. Cada } \\
\text { indivíduo aplicou } \\
\text { batom e a impressão } \\
\text { labial foi coletada } \\
\text { pressionando os } \\
\text { lábios em papel }\end{array}$ & $\begin{array}{l}\text { A espessura dos lábios } \\
\text { foi classificada em: } \\
\text { delgados, médios, } \\
\text { grossos ou muito } \\
\text { grossos e lábios mistos. } \\
\text { A comissura labial foi } \\
\text { analisada segundo a } \\
\text { disposição (hor., abaix., } \\
\text { elev.)A análise da } \\
\text { impressão labial foi feita } \\
\text { segundo a classificação } \\
\text { de Suzuki e Tsuchihashi. }\end{array}$ & 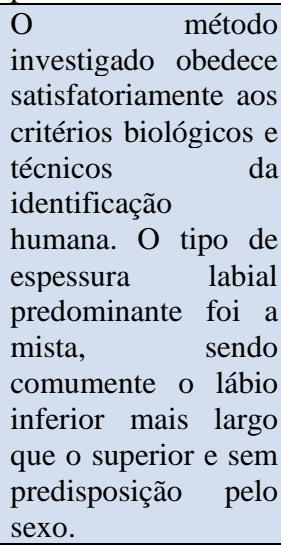 \\
\hline $\begin{array}{l}\text { Padmavathi, } \\
\text { B.N. et } \\
\text { al./2013 }\end{array}$ & Transversal & $\mathrm{N}=250$ & $\begin{array}{l}\text { Documentar e avaliar } \\
\text { diferentes padrões } \\
\text { labiais na população } \\
\text { de Gujarat e } \\
\text { Rajastão, com uma } \\
\text { tentativa de avaliar a } \\
\text { probabilidade de } \\
\text { determinação de } \\
\text { gênero com base no } \\
\text { padrão labial. }\end{array}$ & $\begin{array}{l}\text { Identificação } \\
\text { Humana/ } \\
\text { Determ. de } \\
\text { sexo }\end{array}$ & $\begin{array}{l}\text { Cada indivíduo } \\
\text { aplicou batom e a } \\
\text { impressão labial foi } \\
\text { coletada } \\
\text { pressionando os } \\
\text { lábios em papel e } \\
\text { fotografada. Cada } \\
\text { imagem foi } \\
\text { digitalizada para } \\
\text { ajuste de contraste, } \\
\text { brilho e nitidez. }\end{array}$ & $\begin{array}{l}\text { A análise da impressão } \\
\text { labial foi feita segundo a } \\
\text { classificação de Suzuki } \\
\text { e Tsuchihashi, mas } \\
\text { também inclui dois } \\
\text { outros padrões, pontos e } \\
\text { complexo. }\end{array}$ & $\begin{array}{lr}\text { Nenhuma } & \text { das } \\
\text { impressões labiais foi } \\
\text { idêntica. O padrão do } \\
\text { lábio superior } \\
\text { desempenhou um } \\
\text { papel definido na } \\
\text { determinação do } \\
\text { sexo. O do lábio } \\
\text { inferior não. A } \\
\text { morfologia labial não } \\
\text { variou }\end{array}$ \\
\hline
\end{tabular}




\begin{tabular}{|c|c|c|c|c|c|c|c|c|}
\hline & & & & & & & & $\begin{array}{l}\text { significativamente } \\
\text { entre os sexos. Os } \\
\text { padrões tipo ponto e } \\
\text { complexo ajudaram } \\
\text { na determinação de } \\
\text { gênero. }\end{array}$ \\
\hline $\begin{array}{c}\text { Barros, } \\
\text { G.B/2006 }\end{array}$ & Transversal & $\mathrm{N}=120$ & $\begin{array}{l}\text { Análise } \\
\text { queiloscópica da } \\
\text { amostra estudada. } \\
\text { Realizar pesquisa de } \\
\text { identificação humana } \\
\text { através do banco de } \\
\text { dados formado pelas } \\
\text { fichas queiloscópica. }\end{array}$ & $\begin{array}{l}\text { Identificação } \\
\text { Humana }\end{array}$ & $\begin{array}{l}\text { Mensuração da } \\
\text { espessura labial com } \\
\text { régua milimetrada. } \\
\text { A classificação das } \\
\text { comissuras foi feita } \\
\text { por meio de } \\
\text { fotografias Cada } \\
\text { indivíduo aplicou } \\
\text { batom e a impressão } \\
\text { labial foi coletada } \\
\text { pressionando os } \\
\text { lábios em papel }\end{array}$ & $\begin{array}{l}\text { A espessura labial foi } \\
\text { analisada segundo a } \\
\text { classificação de Santos. } \\
\text { A comissura labial foi } \\
\text { analisada segundo a } \\
\text { disposição (hor., abaix., } \\
\text { elev.) A análise da } \\
\text { impressão labial foi feita } \\
\text { segundo a classificação } \\
\text { de Suzuki e Tsuchihashi. }\end{array}$ & 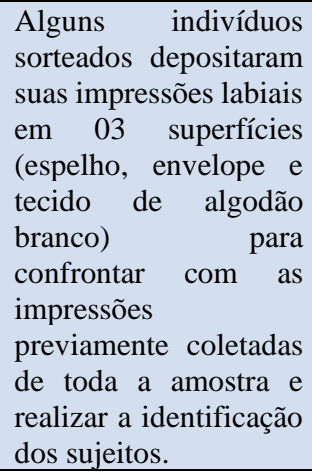 & $\begin{array}{l}\text { A identificação foi } \\
\text { obtida em } 100 \% \text { dos } \\
\text { agentes das } \\
\text { impressões nos } \\
\text { envelopes e nos } \\
\text { espelhos, através da } \\
\text { detecção de no } \\
\text { mínimo 12 } \\
\text { pontos coincidentes. } \\
\text { Nos tecidos, pode-se } \\
\text { excluir cerca de } 90 \% \\
\text { dos suspeitos. }\end{array}$ \\
\hline $\begin{array}{l}\text { Hernandez, } \\
\text { J.C.M. et } \\
\text { al./2015 }\end{array}$ & Transversal & $N=60$ & \begin{tabular}{lr}
\multicolumn{2}{l}{ Identificar os padrões } \\
queiloscópicos & mais \\
frequentes & $\mathrm{em}$ \\
homens e mulheres e \\
estabelecer & $\mathrm{a}$ \\
utilidade & $\mathrm{da}$ \\
queiloscopia & como \\
método & $\mathrm{de}$ \\
identificação. & \\
\end{tabular} & $\begin{array}{l}\text { Identificação } \\
\text { Humana/ } \\
\text { Determ. de } \\
\text { sexo }\end{array}$ & $\begin{array}{l}\text { Cada indivíduo } \\
\text { aplicou batom e a } \\
\text { impressão labial foi } \\
\text { coletada } \\
\text { pressionando os } \\
\text { lábios em papel }\end{array}$ & $\begin{array}{l}\text { A análise da impressão } \\
\text { labial foi feita segundo a } \\
\text { classificação de Suzuki } \\
\text { e Tsuchihashi. }\end{array}$ & --------- & $\begin{array}{l}\text { Cada uma das } \\
\text { impressões era única } \\
\text { e incomparável com } \\
\text { as outras. } \\
\text { Encontraram-se } \\
\text { tendências distintas } \\
\text { entre os padrões de } \\
\text { impressão para cada } \\
\text { sexo. }\end{array}$ \\
\hline $\begin{array}{c}\text { Karki, R.K. et } \\
\text { al./2012 }\end{array}$ & Transversal & $\mathrm{N}=150$ & $\begin{array}{lr}\text { Destacar } & \text { a } \\
\text { importância } & \text { da } \\
\text { impressão labial na } & \text { na } \\
\text { determinação do } & \text { do } \\
\text { sexo relacionada à } \\
\text { investigação forense } \\
\text { para identificação. }\end{array}$ & $\begin{array}{l}\text { Identificação } \\
\text { Humana/ } \\
\text { Determ. de } \\
\text { sexo }\end{array}$ & $\begin{array}{l}\text { Cada indivíduo } \\
\text { aplicou batom e a } \\
\text { impressão labial foi } \\
\text { coletada } \\
\text { pressionando os } \\
\text { lábios em papel }\end{array}$ & $\begin{array}{l}\text { A análise da impressão } \\
\text { labial foi feita segundo a } \\
\text { classificação de Suzuki } \\
\text { e Tsuchihashi. }\end{array}$ & & $\begin{array}{lr}\begin{array}{l}\text { Dois ou } \\
\text { indivíduos mais } \\
\text { tiveram um }\end{array} & \begin{array}{r}\text { não } \\
\text { tipo }\end{array} \\
\text { semelhante } & \text { de } \\
\text { impressão labial. } \\
\text { A análise } & \text { da } \\
\text { impressão labial só } & \text { se } \\
\text { deve ser usada } \\
\text { quando não houver } \\
\text { outros métodos } \\
\text { tradicionais r de } \\
\text { identificação } \\
\text { disponíveis. }\end{array}$ \\
\hline
\end{tabular}




\begin{tabular}{|c|c|c|c|c|c|c|c|}
\hline $\begin{array}{c}\text { Alzapur, A. et } \\
\text { al./2017 }\end{array}$ & Transversal & $\mathrm{N}=100$ & $\begin{array}{l}\text { Estudar a unicidade, } \\
\text { prevalência e a } \\
\text { diferença } r \text { na } \\
\text { determinação do } \\
\text { sexo pelos padrões de } \\
\text { impressão labial. }\end{array}$ & $\begin{array}{l}\text { Identificação } \\
\text { Humana/ } \\
\text { Determ. de } \\
\text { sexo }\end{array}$ & $\begin{array}{l}\text { Cada indivíduo } \\
\text { aplicou batom e a } \\
\text { impressão labial foi } \\
\text { coletada } \\
\text { pressionando os } \\
\text { lábios em papel }\end{array}$ & $\begin{array}{l}\text { A análise da impressão } \\
\text { labial foi feita segundo a } \\
\text { classificação de Suzuki } \\
\text { e Tsuchihashi. }\end{array}$ & $\begin{array}{l}\text { O resultado do nosso } \\
\text { estudo confirma que } \\
\text { as impressões labiais } \\
\text { são únicas como as } \\
\text { impressões digitais e, } \\
\text { portanto, têm } \\
\text { importância forense. } \\
\text { Não há diferença } \\
\text { significativa nos } \\
\text { padrões labiais entre } \\
\text { os sexos. }\end{array}$ \\
\hline $\begin{array}{c}\text { Maloth, A.K. } \\
\text { et al./2016 }\end{array}$ & Transversal & $\mathrm{N}=200$ & $\begin{array}{l}\text { Avaliar a distribuição } \\
\text { do padrão de } \\
\text { contorno labial } \\
\text { entre homens e } \\
\text { mulheres e avaliar os } \\
\text { padrões r de } \\
\text { contorno labial } \\
\text { quanto à rua } \\
\text { singularidade. }\end{array}$ & $\begin{array}{l}\text { Identificação } \\
\text { Humana/ } \\
\text { Determ. de } \\
\text { sexo }\end{array}$ & $\begin{array}{l}\text { Cada indivíduo } \\
\text { aplicou batom no } \\
\text { contorno dos lábios } \\
\text { e a impressão foi } \\
\text { coletada } \\
\text { pressionando os } \\
\text { lábios em papel. }\end{array}$ & $\begin{array}{l}\text { Para classificar o padrão } \\
\text { de contorno labial } \\
\text { seguiu-se o esquema de } \\
\text { classificação proposto } \\
\text { por Chandrashekaran. }\end{array}$ & $\begin{array}{lr}\text { Foram } & \text { observados } \\
\text { dez } & \text { padrões } \\
\text { diferentes } & \text { de } \\
\text { contorno do lábio } \\
\text { superior em } \\
\text { e nulheres } \\
\text { diferentes rover padrões } \\
\text { homens. } \\
\text { contornos dos lábios } \\
\text { são exclusivos de um } \\
\text { indivíduo e não } \\
\text { mudam com o tempo, } \\
\text { portanto também } \\
\text { podem ser usados } \\
\text { como um método de } \\
\text { identificação. }\end{array}$ \\
\hline $\begin{array}{l}\text { Costa, V.A.; } \\
\text { Caldas, } \\
\text { I.M./2012 }\end{array}$ & Transversal & $\mathrm{N}=50$ & $\begin{array}{l}\text { Investigar o papel } \\
\text { potencial } \\
\text { impressões labiais na } \\
\text { identificação } \\
\text { humana. Verificar o } \\
\text { potencial r para } \\
\text { determinação do } \\
\text { sexo a partir da } \\
\text { impressão labial em } \\
\text { uma população } \\
\text { portuguesa. }\end{array}$ & $\begin{array}{l}\text { Identificação } \\
\text { Humana/ } \\
\text { Determ. de } \\
\text { sexo }\end{array}$ & $\begin{array}{l}\text { Cada indivíduo } \\
\text { aplicou batom e a } \\
\text { impressão labial foi } \\
\text { coletada } \\
\text { pressionando os } \\
\text { lábios em papel }\end{array}$ & 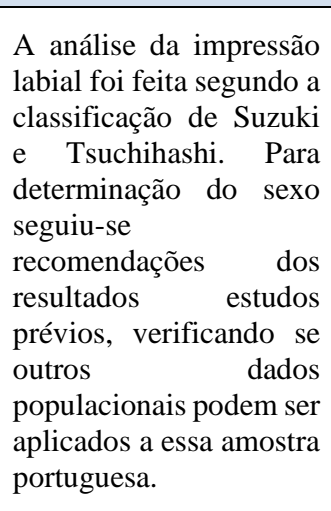 & $\begin{array}{l}\text { Uma impressão } \\
\text { labial pode ser a base } \\
\text { para a identificação. } \\
\text { Os resultados do } \\
\text { presente estudo não } \\
\text { provam que a } \\
\text { determinação do } \\
\text { sexo por meio da } \\
\text { queiloscopia seja } \\
\text { perfeita. No entanto, } \\
\text { parece que estamos } \\
\text { nos aproximando da } \\
\text { validade dessa } \\
\text { técnica. }\end{array}$ \\
\hline
\end{tabular}




\begin{tabular}{|c|c|c|c|c|c|c|c|}
\hline $\begin{array}{l}\text { Moshfegui, M. } \\
\text { et al./2016 }\end{array}$ & Transversal & $N=96$ & $\begin{array}{l}\text { Avaliar as variações } \\
\text { nos padrões labiais } \\
\text { de uma população } \\
\text { iraniana e avaliar as } \\
\text { diferenças entre os } \\
\text { sexos a esse respeito. } \\
\text { Além disso, } \\
\text { determinar a } \\
\text { confiabilidade } \\
\text { validade } \\
\text { impressões labiais. }\end{array}$ & $\begin{array}{l}\text { Identificação } \\
\text { Humana/ } \\
\text { Determ. de } \\
\text { sexo }\end{array}$ & $\begin{array}{l}\text { Cada indivíduo } \\
\text { aplicou batom e a } \\
\text { impressão labial foi } \\
\text { coletada } \\
\text { pressionando os } \\
\text { lábios em papel }\end{array}$ & $\begin{array}{l}\text { A análise da impressão } \\
\text { labial foi feita segundo a } \\
\text { classificação de Suzuki } \\
\text { e Tsuchihashi. Para } \\
\text { avaliar a validade e a } \\
\text { confiabilidade do } \\
\text { método, cada registro } \\
\text { labial foi cegamente } \\
\text { estudado por } 2 \\
\text { examinadores treinados, } \\
4 x \text { em } 4 \text { dias diferentes. } \\
\text { Para determinar a } \\
\text { individualidade das } \\
\text { impressões os lábios } \\
\text { com os mesmos padrões } \\
\text { nos mesmos sextantes } \\
\text { foram diferenciados pela } \\
\text { comparação do do } \\
\text { comprimento dos lábios, } \\
\text { dos ângulos e do padrão } \\
\text { de ramificação dos } \\
\text { sulcos. }\end{array}$ & $\begin{array}{lrr}\text { Não } & \text { foram } \\
\text { observados padrões } \\
\text { de impressão labial } \\
\text { idênticos entre os } \\
\text { sujeitos. Não foi } \\
\text { observada diferença } \\
\text { significativa entre os } \\
\text { padrões de impressão } \\
\text { labial e os } & \text { sexos, } \\
\text { exceto em } & \text { um } \\
\text { sextante. } & & \end{array}$ \\
\hline $\begin{array}{l}\text { EL Domiaty, } \\
\text { M.A.E. et al./ } \\
2010\end{array}$ & Transversal & $\begin{array}{c}\mathrm{N}=966 \\
\text { (sendo } 13 \\
\text { gêmeos } \\
\text { idênticos e } \\
19 \\
\text { famílias) }\end{array}$ & $\begin{array}{l}\text { Estudar os padrões de } \\
\text { impressões labiais de } \\
\text { indivíduos sauditas e } \\
\text { focar a atenção nos } \\
\text { padrões de } \\
\text { impressões labiais de } \\
\text { gêmeos e familiares. }\end{array}$ & $\begin{array}{l}\text { Identificação } \\
\text { Humana }\end{array}$ & $\begin{array}{l}\text { Cada indivíduo } \\
\text { aplicou batom e a } \\
\text { impressão labial foi } \\
\text { coletada } \\
\text { pressionando os } \\
\text { lábios em papel e } \\
\text { fotografada. }\end{array}$ & $\begin{array}{l}\text { A análise da impressão } \\
\text { labial foi feita segundo a } \\
\text { classificação de Renaud. } \\
\text { As impressões que } \\
\text { exibiam o mesmo tipo } \\
\text { de sulco na mesma área } \\
\text { eram diferenciadas pelos } \\
\text { sulcos em outras áreas. }\end{array}$ & $\begin{array}{l}\text { Este } r \text { estudo } \\
\text { demonstrou que o } \\
\text { padrão de impressão } \\
\text { labial é único para } \\
\text { cada um dos } \\
\text { indivíduos } \\
\text { examinados, mesmo } \\
\text { em gêmeos e } \\
\text { familiares. }\end{array}$ \\
\hline $\begin{array}{c}\text { Loganadan, } S . \\
\text { et al./2019 }\end{array}$ & Transversal & $\begin{array}{l}\mathrm{N}=90 \\
\text { (sendo } 30 \\
\text { famílias - } \\
\text { pai, mãe e } \\
\text { um filho) }\end{array}$ & $\begin{array}{l}\text { Descrever o padrão } \\
\text { de impressão labial } \\
\text { em crianças e seus } \\
\text { pais na população } \\
\text { deutero-malaia e } \\
\text { Identificar r a } \\
\text { possibilidade da } \\
\text { criança herdar } \\
\text { padrões de impressão } \\
\text { labial. }\end{array}$ & $\begin{array}{l}\text { Identificação } \\
\text { Humana }\end{array}$ & $\begin{array}{l}\begin{array}{l}\text { Os lábios foram } \\
\text { fotografados } \\
\text { critérios }\end{array} \\
\text { previamente } \\
\text { estabelecidos para } \\
\text { obtenção ra da } \\
\text { imagem. No editor } \\
\text { de imagens } \\
\text { desenhou-se sobre } \\
\text { as linhas dos lábios, }\end{array}$ & $\begin{array}{l}\text { A análise da impressão } \\
\text { labial foi feita segundo a } \\
\text { classificação de Suzuki } \\
\text { e Tsuchihashi. } \\
\text { Admitiram-ser seis } \\
\text { categorias r para } \\
\text { averiguar semelhança } \\
\text { entre as impressões } \\
\text { labiais das crianças e } \\
\text { seus pais. }\end{array}$ & $\begin{array}{l}\text { Verificou-se que } \\
\text { cada indivíduo tem } \\
\text { um padrão único de } \\
\text { impressão labial. A } \\
\text { semelhança do } \\
\text { padrão de impressão } \\
\text { labial entre a mãe e o } \\
\text { filho é maior em } \\
\text { comparação com o } \\
\text { pai e o filho. }\end{array}$ \\
\hline
\end{tabular}


Research, Society and Development, v. 10, n. 8, e50110817401, 2021

(CC BY 4.0) | ISSN 2525-3409 | DOI: http://dx.doi.org/10.33448/rsd-v10i8.17401

\begin{tabular}{|c|c|c|c|c|c|c|c|}
\hline & & & & & $\begin{array}{lr}\text { adotando } & \text { cores } \\
\text { diferentes } & \text { para } \\
\text { diferentes } & \text { padrões } \\
\text { de impressão labial. } \\
\end{array}$ & & \\
\hline $\begin{array}{l}\text { El Domiaty, } \\
\text { M.A.E. et } \\
\text { al./2014 }\end{array}$ & Longitudinal & $\mathrm{N}=116$ & $\begin{array}{lr}\text { Analisou } & \text { as } \\
\text { características } & \text { dos } \\
\text { padrões } & \text { das } \\
\text { impressões labiais e } \\
\text { investigou rou } \\
\text { estabilidade ao longo } \\
\text { dos } \\
\text { comparando novas } \\
\text { impressões tiradas } \\
\text { dos sujeitos com suas } \\
\text { impressões antigas } \\
\text { coletadas três anos } \\
\text { antes. }\end{array}$ & $\begin{array}{l}\text { Identificação } \\
\text { Humana }\end{array}$ & $\begin{array}{l}\text { Cada indivíduo } \\
\text { aplicou batom e a } \\
\text { impressão do lábio } \\
\text { inferior foi coletada } \\
\text { pressionando os } \\
\text { lábios em papel e } \\
\text { fotografada. A } \\
\text { coleta foi realizada } \\
\text { entre set de } 2009 \text { e } \\
\text { outubro de } 2012 \text {. As } \\
\text { impressões antigas } \\
\text { foram armazenadas } \\
\text { nos papéis em } \\
\text { envelopes por } 3 \\
\text { anos, até que as } \\
\text { demais fossem } \\
\text { coletadas pelo } \\
\text { mesmo método dos } \\
\text { mesmos sujeitos. }\end{array}$ & $\begin{array}{l}\text { A análise da impressão } \\
\text { do lábio inferior foi feita } \\
\text { segundo a classificação } \\
\text { de Renaud. O teste de } \\
\text { Mann Whitney foi } \\
\text { utilizado para comparar } \\
\text { a frequência dos padrões } \\
\text { e escores de } \\
\text { similaridade. O valor de } \\
\text { p }<0,05 \text { foi considerado } \\
\text { significativo. }\end{array}$ & $\begin{array}{l}\text { O padrão de } \\
\text { impressão labial é } \\
\text { estável ao longo do } \\
\text { tempo e pode ser } \\
\text { usado como um } \\
\text { auxílio morfológico } \\
\text { em investigações } \\
\text { genéticas e forenses. }\end{array}$ \\
\hline $\begin{array}{l}\text { Lima, } \\
\text { M.V.F.N. et } \\
\text { al./2016 }\end{array}$ & Transversal & $\mathrm{N}=30$ & $\begin{array}{l}\text { Avaliar } \\
\text { praticabilidade das } \\
\text { técnicas de } \\
\text { queiloscopia. Avaliar } \\
\text { a } \\
\text { unicidade das } \\
\text { amostras. Traçar um } \\
\text { perfil das rugas } \\
\text { palatinas e sulcos } \\
\text { labiais de alunos do } \\
\text { curso de Odontologia } \\
\text { da UERN. }\end{array}$ & $\begin{array}{l}\text { Identificação } \\
\text { Humana }\end{array}$ & $\begin{array}{l}\text { Cada indivíduo } \\
\text { aplicou batom e a } \\
\text { impressão labial foi } \\
\text { coletada } \\
\text { pressionando os } \\
\text { lábios em papel e } \\
\text { fotografadas. }\end{array}$ & $\begin{array}{l}\text { A análise da impressão } \\
\text { labial foi feita segundo a } \\
\text { classificação de Suzuki } \\
\text { e Tsuchihashi. }\end{array}$ & $\begin{array}{l}\text { A queiloscopia e a } \\
\text { palatoscopia são } \\
\text { técnicas de } \\
\text { identificação humana } \\
\text { de fácil acesso para } \\
\text { todos. No presente } \\
\text { estudo, as amostras } \\
\text { foram singulares. Os } \\
\text { sulcos labiais mais } \\
\text { encontrados foram } \\
\text { do tipo bifurcado. }\end{array}$ \\
\hline $\begin{array}{l}\text { Saxena, A. et } \\
\text { al./2016 }\end{array}$ & Transversal & $N=159$ & $\begin{array}{l}\text { Avaliar diferenças, se } \\
\text { houver, entre os } \\
\text { padrões de impressão } \\
\text { labial entre homens } \\
\text { nas regiões planas de } \\
\text { Bareilly e nas colinas }\end{array}$ & $\begin{array}{l}\text { Identificação } \\
\text { Humana }\end{array}$ & $\begin{array}{l}\text { Cada indivíduo } \\
\text { aplicou batom e a } \\
\text { impressão labial foi } \\
\text { coletada } \\
\text { pressionando os }\end{array}$ & $\begin{array}{l}\text { A análise da impressão } \\
\text { labial foi feita segundo a } \\
\text { classificação de Suzuki } \\
\text { e Tsuchihashi. }\end{array}$ & $\begin{array}{lr}\text { Não } & \text { foram } \\
\text { encontradas } & \text { duas } \\
\text { impressões } & \text { labiais } \\
\text { similares, } & \text { que } \\
\text { confere credibilidade } \\
\text { ao fato de que as }\end{array}$ \\
\hline
\end{tabular}


Research, Society and Development, v. 10, n. 8, e50110817401, 2021

(CC BY 4.0) | ISSN 2525-3409 | DOI: http://dx.doi.org/10.33448/rsd-v10i8.17401

\section{de Haldwani, Reino}

Unido. lábios em papel e

fotografadas. impressões labiais

podem ser usadas como marcador de identificação

\begin{tabular}{|c|c|c|c|c|c|c|c|}
\hline $\begin{array}{c}\text { Kumar, L. et } \\
\text { al./2017 }\end{array}$ & Transversal & $\mathrm{N}=119$ & $\begin{array}{l}\text { Fornecer uma visão } \\
\text { mais profunda do uso } \\
\text { da queiloscopia na } \\
\text { identificação pessoal. } \\
\text { Identificar o padrão } \\
\text { das impressões } \\
\text { labiais e diferença } \\
\text { entre os sexos nas } \\
\text { impressões labiais no } \\
\text { norte da Índia. }\end{array}$ & $\begin{array}{l}\text { Identificação } \\
\text { Humana/ } \\
\text { Determ. de } \\
\text { sexo }\end{array}$ & $\begin{array}{l}\text { Cada indivíduo } \\
\text { aplicou batom e a } \\
\text { impressão labial foi } \\
\text { coletada } \\
\text { pressionando os } \\
\text { lábios em papel. }\end{array}$ & $\begin{array}{l}\text { A análise da impressão } \\
\text { labial foi feita segundo a } \\
\text { classificação de Suzuki } \\
\text { e Tsuchihashi. }\end{array}$ & $\begin{array}{l}\text { O teste qui-quadrado } \\
\text { apresentou diferença } \\
\text { significativa entre os } \\
\text { sexos. A impressão } \\
\text { labial não coincidiu } \\
\text { entre nenhum dos } \\
\text { indivíduos, } \\
\text { estabelecendo assim } \\
\text { a singularidade das } \\
\text { impressões labiais. }\end{array}$ \\
\hline
\end{tabular}

Fonte: Autores. 
A região geográfica dos estudos variou, sendo 3 estudos no Brasil (Barros, 2006; Oliveira, Rabello \& Fernandes, 2012; Lima, Costa, da Silva, do Nascimento, de Moraes \& de Souza Lucena, 2016) e os demais foram realizados no exterior, como, por exemplo: 10 estudos na Índia (Augustine, Barpande \& Tupkari, 2008; Sharma, Saxena \& Rathod, 2009; Kumar, Vezhavendhan \& Vendhan, 2012; Padmavath, Makkad, Rajan \& Kolli, 2013; Nagalaxmi, Ugrappa, Naga Jyothi, Maloth \& Kodangal, 2014; Maloth et al., 2016; Alzapur et al., 2017; Chaudhari et al., 2017; Kumar, 2017; Jain et al., 2018), 1 no Egito (Ragab et al., 2013), 1 na Colômbia (Hernández, Pabón \& Paredes, 2015), 1 em Portugal (Costa \& Caldas, 2012), 1 no Reino Unido (Saxena, Kumar \& Sharma, 2016), 1 no Irã (Moshfeghi, Beglou, Mortazavi \& Bahrololumi, 2016), 2 na Arábia Saudita (El Domiaty, Al-Gaidi, Elayat, Safwat \& Gathe, 2010; Eldomiaty, Anwar \& Algaidi, 2014), 1 no Nepal (Karki, 2012), e 1 na Indonésia (Loganadan, Dardjan, Murniati, Oscandar, Melinda \& Zakiawat, 2019).

Todos os estudos incluídos na revisão tinham a identificação humana por meio da queiloscopia como objetivo principal. Destes, 15 artigos traziam como variável secundária a estimativa do sexo. Ainda na tabela de extração, quanto à coleta das impressões labiais, todos os participantes usaram batom em seus lábios e os pressionavam sobre o papel.

Outra variável que diferiu substancialmente entre os estudos foram os sistemas utilizados para a classificação das impressões labiais, nos quais 18 artigos seguiram Suzuki e Tsuchihashi (1970) (Barros, 2006; Augustine et al., 2008; Sharma et al., 2009; Kumar et al., 2012; Costa \& Caldas, 2012; Karki, 2012; Oliveira et al., 2012; Padmavathi et al., 2013; Nagalaxmi et al., 2014; Hernández et al., 2015; Lima et al., 2016; Moshfeghi et al., 2016; Saxena et al., 2016; Kumar, Kumar, Alam \& Singh, 2017; Alzapur, Nagothu \& Nalluri, 2017; Chaudhari, Sahay, Kawanpure, Mugadlimath \& Sane, 2017; Loganadan et al., 2019), 2 Renaud (1973) (El Domiaty et al., 2010; Ragab et al., 2013; Eldomiaty et al., 2013), 1 Chandrashekaran (2012) (Maloth, Dorankula \& Pasuula, 2016) e um não utilizou nenhuma das classificações queiloscópicas, como Jain et al. (2018), que atribuiu valores numéricos a partir de pixels das impressões labiais fotografadas. As análises estatísticas realizadas nos estudos para definir o padrão dos sulcos labiais e a sua unicidade envolveram testes T, frequência, teste Z, coeficiente Kappa, Teste QuiQuadrado, Teste exato de Fisher, Teste do Quadrado de Pearson Chi, correlação de Spearman, Teste U de Mann-Whithey, 5 estudos utilizaram estatística descritiva.

Todos os 22 artigos concluíram que a queiloscopia é um método eficaz para a identificação humana, considerando-o um método seguro para ser utilizado no meio forense. Destes, apenas Karki et al. (2012) faz uma ressalva quanto a utilização do método, eles concluem que o método só deve ser usado quando não houver outros métodos tradicionais de identificação disponíveis. Quanto ao dimorfismo sexual, 5 artigos concluíram que é possível identificar o sexo do indivíduo através das impressões labiais, contudo, outros 7 são divergentes e não consideraram que a queiloscopia segura para este fim. Ainda, 2 artigos estudaram a relação dos traços labiais com pessoas de uma mesma família.

Na Tabela 2, verifica-se que a avaliação da qualidade metodológica indicou que todos os estudos atenderam a mais de $80 \%$ dos requisitos de qualidade. A seleção de pacientes dos estudos analisados por esta revisão sistemática apresentou baixo risco de viés em 19 artigos (86,4\%), tendo em vista que, nestes estudos, a amostra foi escolhida por conveniência, havendo preocupação quanto à integridade e saúde dos lábios dos pacientes para que o método fosse aplicado. Em dois estudos (9\%) (Lima et al., 2016; Saxena et al., 2016), não estava clara se houve algum tipo de preocupação com a inclusão de participantes. O trabalho de Moshfeghi et al. (2016) (4,6\%) objetivava determinar o sexo através das impressões labiais, mas a distribuição da amostra foi diferente entre os grupos, pois ele avaliou 22 homens e 74 mulheres, não sendo uma composição equitativa para tal análise, o que pode causar interferência nos seus resultados. Estes três últimos artigos também não tiveram aplicabilidade clara (nos dois primeiros), com um alto risco de viés (o terceiro artigo). 
Tabela 2. Resultados da qualidade metodológica adaptada usando o QUADAS 2.

\begin{tabular}{|c|c|c|c|c|c|c|c|}
\hline \multirow[b]{2}{*}{ ESTUDO } & \multicolumn{4}{|c|}{ RISCO DE VIÉS } & \multicolumn{3}{|c|}{$\begin{array}{l}\text { PREOCUPAÇÃO DE } \\
\text { APLICABILIDADE }\end{array}$} \\
\hline & $\begin{array}{l}\text { Seleção de } \\
\text { Pacientes }\end{array}$ & $\begin{array}{l}\text { Teste } \\
\text { Índice }\end{array}$ & $\begin{array}{l}\text { Referênci } \\
\text { a Padrão }\end{array}$ & $\begin{array}{l}\text { Fluxo e } \\
\text { Tempo }\end{array}$ & $\begin{array}{l}\text { Seleção de } \\
\text { Pacientes }\end{array}$ & $\begin{array}{l}\text { Teste } \\
\text { Índice }\end{array}$ & $\begin{array}{l}\text { Referência } \\
\text { Padrão }\end{array}$ \\
\hline $\begin{array}{l}\text { JAIN et al., } \\
\quad 2018\end{array}$ & ;) & ;) & (:) & $\mathrm{X}$ & $?$ & (:) & (;) \\
\hline $\begin{array}{l}\text { CHAUDHA } \\
\text { RI et al., } \\
2017\end{array}$ & ;) & ;) & (:) & $\mathrm{X}$ & ;) & ;) & ;) \\
\hline $\begin{array}{l}\text { KUMAR et } \\
\text { al., } 2012\end{array}$ & (:) & (:) & (:) & $\mathrm{X}$ & (;) & ;) & ;) \\
\hline $\begin{array}{l}\text { RAGAB et } \\
\text { al., } 2013\end{array}$ & ;) & (-) & ;) & $\mathrm{X}$ & ;) & ;) & ;) \\
\hline $\begin{array}{l}\text { AUGUSTIN } \\
\text { E et al., } \\
2008\end{array}$ & ;) & ;) & ;) & $\mathrm{X}$ & ;:) & ;) & ;) \\
\hline $\begin{array}{l}\text { NAGALAX } \\
\text { MI et al., } \\
2014\end{array}$ & ;) & (:) & ;) & $\mathrm{X}$ & (:) & & ;) \\
\hline $\begin{array}{l}\text { SHARMA } \\
\text { et al., } 2009\end{array}$ & (:) & ;) & ;) & $\mathrm{X}$ & (:) & ;) & ;) \\
\hline $\begin{array}{l}\text { OLIVEIRA } \\
\text { et al., } 2012\end{array}$ & (:) & (:) & (:) & $\mathrm{X}$ & (:) & (:) & (:) \\
\hline $\begin{array}{c}\text { PADMAVA } \\
\text { THI et al., } \\
2013\end{array}$ & ;) & ;) & ;) & $\mathrm{X}$ & $?$ & ;) & ;) \\
\hline $\begin{array}{l}\text { BARROS et } \\
\text { al., } 2006\end{array}$ & (:) & ;) & ;) & $\mathrm{X}$ & (;) & (;) & (:) \\
\hline $\begin{array}{l}\text { HERNAND } \\
\text { EZ et al., } \\
2015\end{array}$ & (;) & ;) & ;) & $\mathrm{X}$ & ;) & ;) & ;) \\
\hline $\begin{array}{l}\text { ALZAPUR } \\
\text { et al., } 2017\end{array}$ & (:) & (:) & ;) & $\mathrm{X}$ & ;) & ;) & ;) \\
\hline $\begin{array}{c}\text { COSTA; } \\
\text { CALDAS } \\
2012\end{array}$ & ;) & ;) & ;) & $\mathrm{X}$ & ;) & ;) & ;) \\
\hline $\begin{array}{c}\text { EL } \\
\text { DOMIATY } \\
\text { et al., } 2010\end{array}$ & ;) & ;) & ;) & $\mathrm{X}$ & ;) & ;) & ;) \\
\hline $\begin{array}{l}\text { ELDOMIA } \\
\text { TY et al., } \\
2014\end{array}$ & (-) & (:) & (;) & $\mathrm{X}$ & (:) & ;) & (;) \\
\hline
\end{tabular}




\begin{tabular}{|c|c|c|c|c|c|c|c|}
\hline $\begin{array}{l}\text { KARKI et } \\
\text { al., } 2012\end{array}$ & (;) & (;) & (;) & $\mathrm{X}$ & (:) & (;) & (;) \\
\hline $\begin{array}{l}\text { KUMAR et } \\
\text { al., } 2017\end{array}$ & (:) & (:) & (:) & $X$ & (:) & (;) & (;) \\
\hline $\begin{array}{l}\text { LIMA et al., } \\
\qquad 2016\end{array}$ & $?$ & (;) & (;) & $\mathrm{X}$ & $?$ & (;) & (;) \\
\hline $\begin{array}{l}\text { LOGANAD } \\
\text { AN et al., } \\
2019\end{array}$ & (;) & (;) & ;) & $\mathrm{X}$ & (;) & (;) & (;) \\
\hline $\begin{array}{l}\text { MALOTH } \\
\text { et al., } 2016\end{array}$ & (;) & ;) & ;) & $X$ & (:) & (;) & (;) \\
\hline $\begin{array}{l}\text { MOSHFEG } \\
\text { HI et al., } \\
2016\end{array}$ & 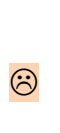 & (;) & (;) & $\mathrm{X}$ & : & (;) & (;) \\
\hline $\begin{array}{l}\text { SAXENA et } \\
\text { al., } 2016\end{array}$ & $?$ & (;) & (;) & $\mathrm{X}$ & $?$ & (;) & (;) \\
\hline
\end{tabular}

(;) Alto Risco

(2) Baixo Risco

Fonte: Autores.

No que tange a condução e interpretação do teste de índice (queiloscopia), não houve, nestes estudos, a introdução de viés, uma vez que os métodos propostos pelos autores, para a realização das impressões labiais, são precisos, como também houve a preocupação de que estes métodos respondessem ao objetivo do estudo. Quanto ao padrão de referência, a sua conduta ou interpretação, todos os estudos apresentaram baixo risco de introduzirem um viés, uma vez que as impressões labiais estão sendo comparadas ao próprio lábio do indivíduo.

A descrição dos pacientes que não receberam o teste índice ou o padrão de referência, disposta no domínio 4 (Fluxo e Tempo) do QUADAS, não se aplica aos estudos dessa revisão, pois todos os pacientes receberam tanto o teste como o padrão de referência. Quanto à questão do intervalo de tempo, os dados referentes ao indivíduo foram coletados quase que simultaneamente à realização do teste índice.

\section{Discussão}

Para que um método de identificação seja confiável, é necessário preencher cinco fundamentos, biológicos e técnicos: a unicidade, imutabilidade, perenidade, praticabilidade e classificabilidade (Gioster-Ramos, 2021). Seguindo tais fundamentos pode-se considerar a queiloscopia um método válido na busca pela identificação humana, pois o mesmo respeita todos os princípios necessários para tal (Molano, Gil, Jaramillo \& Ruiz, 2002).

Dentre os aspectos da unicidade, as impressões labiais são diferentes entre si, assim como diferentes entre os indivíduos, mesmo que estes sejam gêmeos (Suzuki \& Tsuchiahashi, 1971; Molano et al. 2002; Barros, 2006; Caldas et al., 2007; Sharma et al., 2009; El Domiaty et al., 2010; Costa \& Caldas, 2012; Karki, 2012; Kumar et al., 2012; Oliveira et al., 2012; Padmavath et al., 2013; Ragab et al., 2013; Eldomiaty et al., 2014; Nagalaxmi et al., 2014; Hernández et al., 2015; Lima et al., 2016; Maloth et al., 2016; Moshfeghi et al., 2016; Saxena, et al, 2016; Kumar et al., 2017; Jain, Poojitha \& Bhatia, 2018; Loganadan et al., 2019). É considerada imutável, pois pode ser observada que há reparação da forma original dos lábios após uma lesão (Prabhu, Dinkar, Prabhu \& Rao, 2012). São perenes pois mantém-se estáveis ao longo do tempo (Saxena et al., 2016) e, que, por se tratar de tecido mole, não serão úteis se submetidas ao processo de putrefação, em casos lesivos irreversíveis ou carbonização. Possuem 
praticabilidade quando o seu registro pode ser obtido com baixo custo e uma rápida aplicação (Privadharshini, 2018). Quanto ao requisito técnico da classificabilidade, encontramos um impasse devido aos variados sistemas de classificação disponíveis para serem utilizados, não existindo um que seja universal e que facilite o registro e a recuperação da impressão labial, quando da necessidade de um exame comparativo.

No entanto, para Karki (2012), a análise da impressão labial só deve ser usada quando não houver outros métodos tradicionais de identificação disponíveis, pois estes autores não consideram que as impressões labiais sejam tão boas quanto a impressão digital.

Um aspecto importante no que tange a identificação humana é a estimativa do sexo, pois a sua distinção reduzirá as possibilidades em casos de identificação onde se tem um elevado contingente de suspeitos. Sharma et al. (2009) e Nagalaxmi et al. (2014) observam, em seus respectivos estudos, que as impressões labiais se comparadas às rugas palatais são confiáveis na estimativa do sexo. Apesar disso, essa comparação não garante que a queiloscopia seja um método confiável na estimativa sexual. Nos estudos de Kumar (2012), Hernandez et al. (2015) e Kumar et al. (2017) foi possível encontrar diferença nos padrões labiais entre homens e mulheres, afirmando que é possível determinar o sexo do indivíduo através do método. Contudo, tal afirmação é contrariada por Augustine, Barpand e Tuplari (2008); Costa e Caldas (2012), Oliveira et al. (2012), Padmavathi et al. (2013), Moshfegui et al. (2016), Alzapur et al. (2017), Chaudhari et al. (2017) que não encontraram diferenças significativas na distinção sexual. Não foi possível encontrar explicação metodológica (amostral ou estatística) para identificar às conclusões chegadas pelos autores que afirmam haver diferença entre os sexos nos padrões labiais.

Quanto à identificação, de acordo com a região geográfica do indivíduo, não houve o reconhecimento de características nas impressões labiais que levassem à identificação de sua origem. Estudos como os de Kumar et al. (2012), Nagalaxmi et al. (2014), Maloth, Dorankula e Pasupul, (2016), Alzapur et al. (2017) Kumar et al. (2017), Jain et al. (2018) foram realizados em diferentes regiões da Índia e não obtiveram como resultados o mesmo tipo de padrão labial predominante. Ragab, El-Dakrooky, \& Rahman (2013) concluíram que não houve associação entre os padrões labiais e a origem geográfica dos egípcios participantes do seu estudo. Um outro exemplo pode ser encontrado nos estudos de Costa e Caldas (2012), que analisou a população portuguesa, e Saxena et al. (2016), com indivíduos do Reino Unido, que encontraram o padrão Tipo I (classificação de Suzuki e Tsuchihashi) como o mais prevalente de suas, respectivas, amostras.

Não há como negar que a genética é de suma importância dentro de investigações policiais e é margeando por essa área que Augustine et al. (2008) concluíram, analisando 52 famílias, que em $63 \%$ das impressões labiais dos filhos é possível encontrar semelhanças às dos pais. Também é possível encontrar no estudo de Loganadan et al. (2019) tal relação com a hereditariedade, o mesmo analisou 30 famílias e identificou que havia uma maior semelhança entre os padrões de impressão labial de mãe e filho do que em pai e filho. Apesar dos autores citados anteriormente terem utilizado classificações de padrões labiais diferentes, ambos concluem que a queiloscopia pode ser relacionada à características hereditárias.

Uma das limitações desta revisão sistemática diz respeito à impossibilidade de evoluir com uma metanálise e consequente análise da certeza da evidência (GRADE). Tal situação pode ser explicada pela alta variabilidade entre os estudos avaliados, principalmente com relação às metodologias adotadas pelos autores. Um outro fato que limitou esta revisão foi a falta de uma classificação padronizada utilizada pelos estudos para a análise dos sulcos labiais e seu posterior arquivamento, reflexo do que também é observado no cotidiano pericial. Com isso, é importante que futuros estudos busquem um padrão único de classificação para a queiloscopia, assim como investiguem a questão da hereditariedade, ainda pouco estudada.

\section{Considerações Finais}

De acordo com os estudos incluídos nessa revisão sistemática, conclui-se que a queiloscopia é um método eficaz quanto à identificação humana, além de ser rápido e de baixo custo para sua utilização. Destaca-se que este método não pode ser utilizado 
em casos em que há avançado estado de putrefação, carbonização ou quando a região dos lábios apresente patologia grave e irreversível. Em relação à identificação do sexo do indivíduo utilizando a queiloscopia, conclui-se que este não é um método eficaz. A identificação do indivíduo pelas características hereditárias, por meio da queiloscopia, ainda carece de mais estudos, uma vez que não há evidência suficiente que comprove a sua confiabilidade no meio forense.

\section{Referências}

Alzapur, A., Nagothu, R. S., \& Nalluri, H. B. (2017). Impressões labiais - um estudo de sua singularidade entre os alunos do MediCiti Medical College. Jornal indiano de anatomia clínica e fisiologia. 4 (1), 68.

Augustine, J., Barpande, S. R., \& Tupkari, J. V. (2008). Cheiloscopy as an adjunct to forensic identification: A study of 600 individuals. J Forensic Odontostomatol, 26(2), 44-52.

Bangi, B. B., Ginjupally, U., Nadendla, L. K., \& Vadla, B. (2017). 3D evaluation of maxillary sinus using computed tomography: A sexual dimorphic study. International journal of dentistry, 2017.

Barros, G. B. (2006). Queiloscopia: uso da técnica na identificação forense (Doctoral dissertation, Universidade de São Paulo).

Caldas, I. M., Magalhaes, T., \& Afonso, A. (2007). Establishing identity using cheiloscopy and palatoscopy. Forensic science international, 165(1), 1-9.

Castro-Silva, I. I., Silva, O. M. L. D., \& Veiga, B. M. C. (2014). Uso da rugoscopia palatina como ferramenta biométrica: um estudo populacional em NiteróiRJ, Brasil. Revista de Odontologia da UNESP, 43(3), 203-208.

Chaudhari, S. H., Sahay, S., Kawanpure, H., Mugadlimath, A., Sane, M., \& Gathe, B. (2017). A Study of Cheiloscopic Patterns in Chhattisgarh Population. Indian Journal of Forensic Medicine \& Toxicology, 11(2).

Costa, V. A., \& Caldas, I. M. (2012). Morphologic patterns of lip prints in a Portuguese population: a preliminary analysis. Journal of Forensic Sciences, 57(5), $1318-1322$

El Domiaty, M. A., Al-Gaidi, S. A., Elayat, A. A., Safwat, M. D. E., \& Galal, S. A. (2010). Morphological patterns of lip prints in Saudi Arabia at Almadinah Almonawarah province. Forensic science international, 200(1-3), 179-e1.

Eldomiaty, M. A., Anwar, R. I., \& Algaidi, S. A. (2014). Stability of lip-print patterns: a longitudinal study of Saudi females. Journal of forensic and legal medicine, 22, 154-158.

Gioster-Ramos, M. L., Silva, E. C. A., Nascimento, C. R., da Silva Fernandes, C. M., \& da Costa Serra, M. (2021). Técnicas de identificação humana em Odontologia Legal. Research, Society and Development, 10(3).

Gioster-Ramos, M. L., Silva, E. C. A., Nascimento, C. R., da Silva Fernandes, C. M., \& da Costa Serra, M. (2021). Técnicas de identificação humana em Odontologia Legal. Research, Society and Development, 10(3).

Hernández, J. C. M., Pabón, Y. N. O., Paredes, J. F. M. (2015). Identificación de sexo mediante queiloscopia en Santander: una herramienta para la medicina forense. Estudio inicial. Revista espanhola de medicina legal. 41(3), pp. 111-116.

Jain, S., Poojitha, V., \& Bhatia, M. (2018). A cheiloscopic approach for unique identification among indian subpopulation. In Intelligent Communication, Control and Devices (pp. 1729-1738). Springer, Singapore.

Karki, R. K. (2012). Lip prints-an identification aid. Kathmandu University Medical Journal, 10(2), 55-57.

Kumar, G. S., Vezhavendhan, N., \& Vendhan, P. (2012). A study of lip prints among Pondicherry population. Journal offorensic dental sciences, 4(2), 84.

Kumar, L., Kumar, N., Alam, S., \& Singh, B. (2017). Forensic Anthropology-Lip Print Pattern in North Indians. Journal of Punjab Academy of Forensic Medicine \& Toxicology, 17(2).

Lima, M. V. D. F. N., Costa, G. M., da Silva, V. B., do Nascimento, M. R., de Moraes, H. H., \& de Souza Lucena, E. E. (2016). Verificação da praticabilidade e da unicidade na queiloscopia e na palatoscopia como métodos de identificação humana. Revista Brasileira de Odontologia Legal, 3(1).

Loganadan, S., Dardjan, M., Murniati, N., Oscandar, F., Malinda, Y., \& Zakiawati, D. (2019). Preliminary research: description of lip print patterns in children and their parents among Deutero-Malay population in Indonesia. International journal of dentistry, 2019.

Maloth, A. K., Dorankula, S. P. R., \& Pasupula, A. P. (2016). Lip outline: A new paradigm in forensic sciences. Journal offorensic dental sciences, 8(3), 178.

Moher, D., Liberati, A., Tetzlaff, J., Altman, DG, \& Prisma Group. (2009). Itens de relatório preferidos para revisões sistemáticas e meta-análises: a declaração PRISMA. Medicamento PLoS , 6 (7), e1000097.

Molano, M. A., Gil, J. H., Jaramillo, J. A., \& Ruiz, S. M. (2002). Estudio queiloscópico en estudiantes de la Facultad de Odontología de la Universidad de Antioquia. Revista Facultad De Odontología Universidad De Antioquia, 14(1).

Moshfeghi, M., Beglou, A., Mortazavi, H., \& Bahrololumi, N. (2016). Morphological patterns of lip prints in an Iranian population. Journal of clinical and experimental dentistry, 8(5), e550. 
Research, Society and Development, v. 10, n. 8, e50110817401, 2021

(CC BY 4.0) | ISSN 2525-3409 | DOI: http://dx.doi.org/10.33448/rsd-v10i8.17401

Nagalaxmi, V., Ugrappa, S., Naga Jyothi, M., Ch, L., Maloth, K. N., \& Kodangal, S. (2014). Cheiloscopy, Palatoscopy and Odontometrics in Sex Prediction and Dis-crimination-a Comparative Study. The open dentistry journal, 8, 269.

Oliveira, J. A., Rabello, P. M., \& Fernandes, L. C. C. (2012). Estudo queiloscópico em graduandos de odontologia. Pesquisa Brasileira em Odontopediatria e Clínica Integrada, 12(4), 521-528.

Padmavathi, B. N., Makkad, R. S., Rajan, S. Y., \& Kolli, G. K. (2013). Gender determination using cheiloscopy. Journal of forensic dental sciences, 5(2), 123. Page, M., Lain, R., Kemp, R., \& Taylor, J. (2018). Validation studies in forensic odontology-Part 1: Accuracy of radiographic matching. Science \& Justice, 58(3), 185-190

Prabhu, R. V., Dinkar, A. D., Prabhu, V. D., \& Rao, P. K. (2012). Cheiloscopy: revisited. Journal of forensic dental sciences, $4(1), 47$.

Priyadharshini, K. I., Ambika, M., Sekar, B., Mohanbabu, V., Sabarinath, B., \& Pavithra, I. (2018). Comparison of cheiloscopy, odontometric, and facial index for sex determination in forensic dentistry. Journal of forensic dental sciences, 10(2), 88.

Ragab, A. R., El-Dakroory, S. A. E. A., \& Rahman, R. H. A. (2013). Characteristic patterns of lip prints in Egyptian population sample at Dakahlia Governorate. International journal of legal medicine, 127(2), 521-527.

Reddy, L. V. K. (2011). Lip prints: An overview in forensic dentistry. Journal of Advanced Oral Research, 2(1), 17-20.

Saxena, A., Kumar, V., \& Sharma, S. (2016). Comparative Study of Lip Print Pa ern among Males in Hilly and Plain Region of North India. Prof. RK Sharma, $10(2), 6$.

Sharma, P., Saxena, S., \& Rathod, V. (2009). Comparative reliability of cheiloscopy and palatoscopy in human identification. Indian Journal of Dental Research, 20(4), 453.

Singh, J., Gupta, K. D., Sardana, V., Balappanavar, A. Y., \& Malhotra, G. (2012). Sex determination using cheiloscopy and mandibular canine index as a tool in forensic dentistry. Journal of forensic dental sciences, 4(2), 70.

Suzuki, K., \& Tsuchiahashi, Y. (1971). A new attempt of personal identification by means of lip print. Canadian Society of Forensic Science Journal, 4(4), 154158.

Tornavoi, D. C., \& da Silva, R. H. A. (2010). Rugoscopia palatina e a aplicabilidade na identificação humana em odontologia legal: revisão de literatura. Saúde, Ética \& Justiça, 15(1), 28-34.

Verghese, A. J., Somasekar, M., \& Umesh Babu, R. (2010). A study on lip print types among the people of Kerala. J Indian Acad Forensic Med, 32(1). 